\title{
Seroprevalence of Toxoplasma gondii infection in pet dogs in Lanzhou, Northwest China
}

\author{
Song-Ming Wu ${ }^{1,3}$, Si-Yang Huang ${ }^{1}$, Bao-Quan Fu', Guang-Yuan Liu', Jia-Xu Chen ${ }^{4}$, Mu-Xin Chen ${ }^{4}$, Zi-Guo Yuan ${ }^{3}$, \\ Dong-Hui Zhou ${ }^{1,3}$, Ya-Biao Weng ${ }^{3}$, Xing-Quan Zhu' ${ }^{1,5,6}$ and De-He Ye 2* $^{2^{*}}$
}

\begin{abstract}
Background: In recent years, surveys of Toxoplasma gondii infection in dogs have been reported worldwide, including China. However, little is known about the prevalence of $T$. gondii in pet dogs in Northwest China. In the present study, the prevalence of T. gondii in pet dogs in Lanzhou, China was investigated using the modified agglutination test (MAT).

Results: In this survey, antibodies to T. gondii were found in 28 of 259 (10.81\%) pet dogs, with MAT titers of 1:20 in 14 dogs, 1:40 in nine, 1:80 in four, and 1:160 or higher in one dog. The prevalence ranged from $6.67 \%$ to $16.67 \%$ among dogs of different ages, with low rates in young pet dogs, and high rates in older pet dogs. The seroprevalence in dogs $>3$ years old was higher than that in dogs $\leq 1$ years old, but the difference was not statistically significant $(P>0.05$ ). The seroprevalence in male dogs was $12.50 \%$ (17 of 136), and in female dogs it was $8.94 \%$ (11 of 123), but the difference was not statistically significant $(P>0.05)$.
\end{abstract}

Conclusions: A high prevalence of T. gondii infection was found in pet dogs in Lanzhou, Northwest China, which has implications for public health in this region. In order to reduce the risk of exposure to T. gondii, further measures and essential control strategies should be carried out rationally in this region.

\section{Background}

Toxoplasma gondii is an important zoonotic intracellular protozoan parasite, which can affect all warm-blooded mammals and birds throughout the world, including humans $[1,2]$. T. gondii is transmitted by ingestion of tissue cysts from undercooked or raw meat, consumption of food or drink contaminated with oocysts, or ingestion of oocysts from the environment by accident [1]. Nearly one third of the global human population has been infected with $T$. gondii, however, infection in healthy individuals is usually asymptomatic and only a small percentage of exposed people have obvious clinical symptoms $[1,3,4]$. Nonetheless, if $T$. gondii infection occurs in pregnant women it can cause severe disease such as toxoplasmic encephalitis, blindness, abortion, fetal abnormalities or even prenatal death [5]. Infection of immunocompromised patients (e.g. HIV/AIDS

\footnotetext{
* Correspondence: gndydh@126.com

${ }^{2}$ College of Veterinary Medicine, Gansu Agricultural University, Lanzhou, Gansu Province 730070, PR China

Full list of author information is available at the end of the article
}

patients) with $T$. gondii can cause acute morbidity and even death $[6,7]$.

Pet dogs are often regarded as the faithful friends and intimate companions of humans. Unfortunately, $T$. gondii oocysts in pet dogs can traverse the intestinal tract and finally be excreted in the feces [8], which can pose a threat to human health, particularly in pregnant women and immunologically deficient people as described above. Investigations of the prevalence of antibodies to $T$. gondii in dogs have been conducted extensively in the world [9-14], however, only limited surveys of $T$. gondii infection in pet dogs have been reported. In recent years, there also have been various surveys of $T$. gondii infection in dogs in the People's Republic of China (PRC) [Table 1, [15-26]], but in Northwest China only one such investigation of pet dogs has been reported in Inner Mongolia [16].

The objectives of the present survey were to determine the seroprevalence of $T$. gondii infection in pet dogs in Lanzhou, the capital of Gansu province, Northwest China, and to evaluate the main associated risk factors relating to exposure to $T$. gondii in this region. In

\section{Ciomed Central}


Table 1 Prevalence of $T$. gondii infection in dogs in People's Republic of China

\begin{tabular}{|c|c|c|c|c|c|c|}
\hline Provinces/Cities & No. tested & $\begin{array}{l}\text { Positive } \\
\text { (\%) }\end{array}$ & Serologic test ${ }^{d}$ & Cut-off value & $\begin{array}{l}\text { Time tested } \\
\text { (year) }\end{array}$ & References \\
\hline \multirow[t]{2}{*}{ Guangzhou } & $114^{a}$ & 17.5 & ELISA & $U N^{e}$ & $2007-2008$ & [15] Zhang et al., 2010 \\
\hline & $36^{\mathrm{b}}$ & 33.3 & & & & \\
\hline \multirow[t]{3}{*}{ Inner Mongolia } & $68^{\mathrm{a}}$ & 7.4 & ELISA & UN & 2009-2010 & [16] Lu et al., 2010 \\
\hline & $35^{\mathrm{c}}$ & 2.9 & & & & \\
\hline & $64^{\mathrm{b}}$ & 23.4 & & & & \\
\hline Shenzhen & $598^{\mathrm{a}}$ & 3.34 & ELISA & UN & 2009-2010 & [17] Xie et al., 2010 \\
\hline Zhengzhou & $106^{\mathrm{a}}$ & 12.26 & $\mathbb{H A}$ & $1: 64$ & 2009 & [18] Zhang et al., 2010 \\
\hline Xinjiang & $96^{\mathrm{b}}$ & 4.17 & $\mathbb{H A}$ & $1: 64$ & UN & [19] Zhang et al., 2009 \\
\hline \multirow[t]{4}{*}{ Shanghai } & $360^{\mathrm{a}}$ & 11.67 & PAPS & UN & $2001-2002$ & [20] Gong et al., 2009 \\
\hline & $620^{\mathrm{a}}$ & 4.03 & $\mathrm{HA}$ & $1: 64$ & 2003-2007 & \\
\hline & $355^{\mathrm{a}}$ & 4.51 & PAPS & UN & 2008-2009 & \\
\hline & $355^{\mathrm{a}}$ & 3.94 & $\mathrm{HA}$ & $1: 64$ & 2008-2009 & \\
\hline Shanghai & $3982^{\mathrm{a}}$ & 13.00 & PAPS & UN & 2002 & [21] Wang et al., 2006 \\
\hline Taizhou & $5248^{\mathrm{a}}$ & 0.26 & UN & UN & $2007-2008$ & [22] Lu et al., 2009 \\
\hline Haikou & $462^{\mathrm{a}}$ & 2.6 & ELISA & UN & $2007-2008$ & [23] Huang et al., 2008 \\
\hline Dongguan & $610^{c}$ & 0.66 & $\| \mathrm{HA}$ & $1: 64$ & $2005-2006$ & [24] Zhang et al., 2007 \\
\hline Beijing & $159^{\mathrm{a}}$ & 13.21 & ELISA & UN & UN & [25] Yu et al., 2006 \\
\hline Hebei & $78^{c}$ & 26.92 & ELISA & UN & $2000-2001$ & [26] Yuan et al., 2004 \\
\hline
\end{tabular}

${ }^{a}$ pet dogs, ${ }^{b}$ stray dogs, ${ }^{c}$ type not specified by others.

${ }^{d}$ ELISA: enzyme-linked immunosorbent assay, PAPS: polyaledehyde polystyrene, IHA: indirect hemagglutination test

e UN: unknown

the present paper, we also summarise serological surveys of the prevalence of $T$. gondii infection in dogs in China (Table 1), because most of these surveys were originally published in local Chinese journals [16-26], which are not accessible to international readers.

\section{Materials and methods}

\section{The study site}

The study was conducted in Lanzhou Municipality, the capital of Gansu province, covering an area of 13,085 square meters in Northwest China. Lanzhou is situated in the geometric center of China's territory between east longitudes of $102^{\circ} 30^{\prime \prime}$ to $104^{\circ} 30^{\prime \prime}$ and north latitudes of $35^{\circ} 5^{\prime \prime}$ to $38^{\circ}$, which has an average height of 1,500 meters above sea level. The city is located between mountains to the north and south, and is crossed by the Yellow River from west to east, with a characteristic of ribbon basin geography. It has a typical temperate and monsoonal continental climate, with an annual rainfall of $360 \mathrm{~mm}$ mainly from June to September, an average annual temperature of $9.3^{\circ} \mathrm{C}$, average yearly sunlight exposure of 2,446 hours and a frost-free season of about 180 days.

\section{Sampling of pet dogs}

A total of 259 blood samples were collected from the leg veins of pet dogs between November and December 2010 in Lanzhou. These pet dogs were admitted into pet hospitals located in four districts of Lanzhou City, including Chengguan District, Anning District, Xigu District and Qilihe District, with a variety of diseases. Pet dog owners were asked for details of the animals breed, age, sex, source and medical history using a structured questionnaire. Blood samples were kept at $37^{\circ} \mathrm{C}$ for $2 \mathrm{~h}$ and centrifuged at $2,000 \mathrm{~g}$ for $5 \mathrm{~min}$. The resulting sera samples were stored at $-20^{\circ} \mathrm{C}$ until further analysis.

\section{Serological examination}

Sera from pet dogs were diluted in a two-fold serial dilution from 1:20 to 1:320 and investigated for $T$. gondii antibodies using the modified agglutination test (MAT) as described previously [27]. MAT is a sensitive and specific technique for measuring $T$. gondii antibodies, which has been used extensively in experimentally and naturally infected dogs $[11,13,28]$, and other animals [29]. Briefly, MAT was performed with a suspension of Toxoplasma tachyzoites fixed with formalin, serum samples which had been diluted in phosphate buffered saline (PBS, $\mathrm{pH} 7.2$ ), positive and negative control sera, antigen diluting buffer containing bovine serum albumin (BSA), 2-mercaptoethanol [to deplete the sera of nonspecific immunoglobulin (Ig) M antibody], and Evans blue dye solution. MAT titers of 1:20 or higher were considered as positive [12], and those sera with dubious results were re-tested. Positive and negative controls were incorporated in each test and tested at the same dilutions of sera samples. A negative result was returned 
when the base of the " $U$ " bottom 96 well microtiter plates contained a blue pellet; conversely a clear bottom indicated a positive result.

\section{Statistical analyses}

Differences in the seroprevalence of $T$. gondii infected pet dogs between male and female dogs, and different age groups were analyzed using a Chi square test in Predictive for Analytics Software (PASW ${ }^{\circledR}$ ) Statistics 18. The $P$ value $<0.05$ was considered statistically significant. The correlation between the rates of infection in different age groups was calculated with Excel 2003 $\left(\right.$ Microsoft $\left.{ }^{\mathbb{R}}\right)$.

\section{Results}

In the present study, a total of 259 pet dogs (123 females and 136 males) from Lanzhou were examined by MAT. Out of these samples, 28 (10.81\%) were seropositive for $T$. gondii. Among these positive pet dogs, seroprevalence varied in different age groups, ranging from $6.67 \%$ to $16.67 \%$ (Table 2). The investigation also showed that the prevalence in female animals was $8.94 \%$, and $12.50 \%$ in male animals (Table 2). Table 3 indicates that antibodies to $T$. gondii were found in 28 (10.81\%) of 259 pet dogs at the cut-off of 1:20, with titers of 1:20 in 14 dogs, 1:40 in nine, 1:80 in four, and 1:160 or higher in one pet dog.

\section{Discussion}

The present investigation showed that the overall seropositivity for $T$. gondii exposure was $10.81 \%$ in pet dogs in Lanzhou, which was lower than the values of $17.5 \%$ in dogs in a study performed in Guangzhou [15], $12.26 \%$ in Zhengzhou [18], and $13.21 \%$ in Beijing [25], but higher than those observed in Inner Mongolia [16], Haiko [23] and Shenzhen [17]. Among these regions, the difference in $T$. gondii seroprevalence may be due to ecological and geographical factors, as well as feeding and animal welfare conditions for dogs in these areas.

It is known that the average annual rainfall of Lanzhou is only $360 \mathrm{~mm}$, and the average annual temperature is $9.3^{\circ} \mathrm{C}$, with a typical continental monsoon

\begin{tabular}{|c|c|c|c|c|c|c|c|}
\hline \multirow[t]{2}{*}{$\begin{array}{l}\text { Biometric } \\
\text { data }\end{array}$} & \multicolumn{2}{|c|}{ Gender } & \multirow[t]{2}{*}{ Total } & \multicolumn{4}{|c|}{$\begin{array}{l}\begin{array}{l}\text { Age } \\
\text { (years) }\end{array} \\
\end{array}$} \\
\hline & Male & Female & & $\leq 1$ & 2 & 3 & $>3$ \\
\hline Sample No. & 136 & 123 & 259 & 121 & 66 & 30 & 42 \\
\hline Positive No. & 17 & 11 & 28 & 9 & 10 & 2 & 7 \\
\hline $\begin{array}{l}\text { Prevalence } \\
\text { (\%) }\end{array}$ & 12.50 & 8.94 & 10.81 & 7.44 & 15.15 & 6.67 & 16.67 \\
\hline
\end{tabular}

Table 3 Antibody titers to Toxopalsma gondii infection in pet dogs in Lanzhou, northwest China by modified agglutination test (MAT)

\begin{tabular}{llllll}
\hline Age group (years) & \multicolumn{5}{c}{ No. of sera with MAT titers of } \\
\cline { 2 - 6 } & $\mathbf{1 : 2 0}$ & $\mathbf{1 : 4 0}$ & $\mathbf{1 : 8 0}$ & $\mathbf{1 : 1 6 0}$ & $\geqq 1: 20$ \\
\hline$\leq 1$ & 6 & 2 & 0 & 1 & 9 \\
2 & 4 & 4 & 2 & 0 & 10 \\
3 & 1 & 1 & 0 & 0 & 2 \\
$>3$ & 3 & 2 & 2 & 0 & 7 \\
Total & 14 & 9 & 4 & 1 & 28 \\
\hline
\end{tabular}

climate. Dry and cold circumstances may be a challenge for the survival of $T$. gondii oocysts, and unfavorable for epidemics of toxoplasmosis.

In comparison with other age groups of dogs, a higher prevalence of infection was detected in the group of dogs $>3$ years old. Although the difference was not statistically significant among age groups $(p>0.05)$, there is a general tendency for older animals to have had more exposure to T. gondii. Older animals have had more opportunities to come into contact with felids, so they may be more likely to acquire $T$. gondii infection by ingesting food contaminated with oocysts which have been shed and excreted in feces by cats. There were limited data on seroprevalence of $T$. gondii infection in cats in Lanzhou, our preliminary survey showed that the seroprevalence of $T$. gondii infection in pet cats in Lanzhou was $22.83 \%$ (unpublished data), indicating a high risk as a source of $T$. gondii infection in dogs and other animals and humans.

In addition to being infected by $T$. gondii oocysts shed and excreted in feces by infected cats, dogs may also become infected through ingestion of raw or uncooked meat/flesh contaminated with T. gondii cysts. Moreover, congential $T$. gondii infection in dogs is considered an important factor, the fetus may acquire initially $T$. gondii infection during pregnancy in female canines. A study found that reinfected pregnant female canines could transplacentally transmit $T$. gondii to their neonates [30]. Another study showed that dogs can vertically transmit $T$. gondii to their offspring by semen [31].

Statistical analysis showed that differences in T. gondii infection between female and male pet dogs were not significant $(p>0.05)$, suggesting that gender of the host is not a crucial factor for $T$. gondii infection. In this study, we found a low (8.06\%) prevalence of $T$. gondii infection in pet dogs in Anning District, compared with a seropositive rate of $9.52 \%$ in Qilihe District, $10.11 \%$ in Chengguan District and 13.79\% in Xigu District, but statistical analyses showed that these differences were not significant $(p>0.05)$.

In this study, we investigated the seroprevalence of $T$. gondii infection in 259 pet dogs from four districts in 
Lanzhou, northwest China between November to December, 2010. The number of pet dogs sampled was large enough to be representative, with the potential limitation that the results of the present investigation may not reflect the actual seroprevalence in other seasons, and in other districts of Lanzhou. Therefore, further comprehensive surveys of $T$. gondii infection in pet dogs in Lanzhou are warranted to sample more pet dogs during each climatic season and from all of the 8 districts and counties of Lanzhou. Also, T. gondii infection in stray dogs in Lanzhou will be considered in further investigations.

\section{Conclusions}

The results of the present survey revealed a high prevalence of $T$. gondii infection in pet dogs in Lanzhou, especially in older pet dogs, which has public health significance because a previous survey of $T$. gondii infection in people with high risk of exposure to T. gondii in Lanzhou showed that $34.78 \%$ of pet dog owners were seropositive [32]. Therefore, it is necessary to take integrated strategies, including efficient management measures to prevent and control T. gondii infection in pet dogs, which could help to reduce $T$. gondii infection in other animals and humans in this area.

\section{Acknowledgements}

This work is supported, in part, by the National S \& T Major Program (Grant No. 2008ZX10004-011, 2009ZX10004-302, 2009ZX10004-201), the National Key Technology R \& D Program (Grant No. 2008BAI56B03), the State Key Laboratory of Veterinary Etiological Biology, Lanzhou Veterinary Research Institute, Chinese Academy of Agricultural Sciences (SKLVEB2009KFKT014 and SKLVEB2010KFKT010), the Special Fund for Agro-scientific Research in the Public Interest (Grant No. 200803017), the Program for Changjiang Scholars and Innovative Research Team in University (Grant No. IRT0723) and the Yunnan Provincial Program for Introducing High-level Scientists (Grant No. 2009(1125). The authors thank Dr J. P. Dubey, Animal Parasitic Diseases Laboratory, Animal and Natural Resources Institute, Beltsville Agricultural Research Center, United States Department of Agriculture, USA for providing the Toxoplasma gondii MAT antigen. Dr Alasdair Nisbet, Parasitology Division, Moredun Research Institute, Scotland, UK is thanked for improving the manuscript.

\section{Author details \\ 'State Key Laboratory of Veterinary Etiological Biology, Key Laboratory of Veterinary Parasitology of Gansu Province, Lanzhou Veterinary Research Institute, CAAS, Lanzhou, Gansu Province 730046, PR China. ${ }^{2}$ College of Veterinary Medicine, Gansu Agricultural University, Lanzhou, Gansu Province 730070, PR China. ${ }^{3}$ College of Veterinary Medicine, South China Agricultural University, Guangzhou, Guangdong Province 510642, PR China. ${ }^{4}$ National Institute of Parasitic Diseases, Chinese Center for Disease Control and Prevention, Laboratory of Parasite and Vector Biology, Ministry of Health, WHO Collaborating Center for Malaria, Schistosomiasis and Filariasis, Shanghai 200025, PR China. ${ }^{5}$ College of Animal Science and Technology, Yunnan Agricultural University, Kunming, Yunnan Province 650201, PR China. ${ }^{6}$ College of Veterinary Medicine, Hunan Agricultural University, Changsha, Hunan Province 410128, PR China.}

\section{Authors' contributions}

$X Q Z$ and DHY conceived and designed the study, and critically revised the manuscript. BQF GYL, JXC, MXC and YBW participated in study design, study implementation and manuscript revision. SMW, SYH and DHZ performed the experiments, analysed the data and drafted the manuscript. BQF, GYL, JXC, MXC and ZGY helped in study implementation and data collection. All authors read and approved the final manuscript.

\section{Competing interests}

The authors declare that they have no competing interests.

Received: 19 March 2011 Accepted: 4 May 2011 Published: 4 May 2011

\section{References}

1. Dubey JP: Toxoplasmosis of Animals and Humans. CRC Press Inc. Second edition. Boca Raton, New York;1-313.

2. Webster JP: Review of "Toxoplasmosis of Animals and Humans (Second Edition)" by J.P. Dubey. Parasit Vectors 2010, 3:112.

3. Tenter AM, Heckeroth AR, Weiss LM: Toxoplasma gondii: from animals to humans. Int J Parasitol 2000, 30:1217-1258.

4. Abu-Madi MA, Al-Molawi N, Behnke JM: Seroprevalence and epidemiological correlates of Toxoplasma gondii infections among patients referred for hospital-based serological testing in Doha, Qatar. Parasit Vectors 2008, 1:39.

5. Cook AJ, Gilbert RE, Buffolano W, Zufferey J, Petersen E, Jenum PA, Foulon W, Semprini AE, Dunn DT: Sources of Toxoplasma infection in pregnant women: European multicentre case-control study. Br Med J 2000, 312:142-147

6. Belanger F, Derouin F, Grangeot-Keros L, Meyer L, the HEMOCO and SEROCO Study Groups: Incidence and risk factors of toxoplasmosis in a cohort of human immunodeficiency virus-infected patients: 1988-1995. Clin Infect Dis 1999, 28:575-581.

7. Montoya JG, Liesenfeld O: Toxoplasmosis. Lancet 2004, 363:1965-1976.

8. Lindsay DS, Dubey JP, Butler JM, Blagburn BL: Mechanical transmission of Toxop-lasma gondii oocysts by dogs. Vet Parasitol 1997, 73:27-33.

9. Simsek S, Utuk AE, Babur C, Koroglu E: Seroprevalence of Toxoplasma gondii in dogs in the province of Kocaeli. Turkiye Parazitol Derg 2006, 30:171-174.

10. Dubey JP, Alvarado-Esquivel C, Liesenfeld O, Herrera-Flores RG, RamirezSanchez BE, Gonzalez-Herrera A, Martinez-Garcia SA, Bandini LA, Kwok OC: Neospora caninum and Toxoplasma gondii antibodies in dogs from Durango City, Mexico. J Parasitol 2007, 93:1033-1035.

11. Dubey JP, Cortes-Vecino JA, Vargas-Duarte JJ, Sundar N, Velmurugan GV Bandini LM, Polo $\amalg$, Zambrano L, Mora LE, Kwok OC, Smith T, Su C. Prevalence of Toxoplasma gondii in dogs from Colombia, South America and genetic characterization of T. gondii isolates. Vet Parasitol 2007, 145:45-50.

12. Dubey JP, Rajapakse RP, Wijesundera RR, Sundar N, Velmurugan GV, Kwok OC, Su C: Prevalence of Toxoplasma gondii in dogs from Sri Lanka and genetic characterization of the parasite isolates. Vet Parasitol 2007, 146:341-346.

13. Dubey JP, Stone D, Kwok OC, Sharma RN: Toxoplasma gondii and Neospora caninum antibodies in dogs from Grenada, West Indies. $J$ Parasitol 2008, 94:750-751.

14. Kamani J, Mani AU, Kumshe HA, Dogo Gl, Yidawi JP, Pauline DK, Nnabuife HE, Joan P, Egwu GO: Serosurvey for Toxoplasma gondii in dogs in Maiduguri, Borno State, Nigeria. J Infect Dev Ctries 2010, 4:15-18.

15. Zhang $H$, Zhou DH, Chen $Y Z$, Lin RQ, Yuan ZG, Song HQ, Li SJ, Zhu XQ: Antibodies to Toxoplasma gondii in stray and household dogs in Guangzhou, China. J Parasitol 2010, 96:671-672.

16. Lu AT, Gao Y, Du S: Survey on cats and dogs infected with Toxoplasma gondii in some areas of inner mongolia. Ani Husbandry Feed Sci 2010, 31:155-156, (in Chinese).

17. Xie GP, Geng YJ, Zhang RL, Huang DN, Gao ST, Zhang Q, Wu S: Survey of Toxoplasma gondii infection in pet cats and dogs in Shenzhen. Chin Trop Med 2010, 10:1075-1077, (in Chinese).

18. Zhang HC, Li PW, Cai JT: Survey of Toxoplasma gondii infection in pet cats and dogs in Zhengzhou. Heilongjiang J Ani Sci Vet Med 2010, 10:74-75, (in Chinese).

19. Zhang YF, Liu FY, Xu XP, He LX, Li AQ, Zhang XS: Toxoplasmosis serological test at northern regions in Xinjiang. Grass-feeding Livestock 2009, 4:22-24, (in Chinese).

20. Gong GH, Zhou JP, Sun QY, Liu PH, Wang Q: Serological survey of Toxoplasma gondii infection in dogs in Shanghai area. Chin J Ani Infect Dis 2009, 17:64-67, (in Chinese). 
21. Wang Q, Liu GQ, Chen YJ, Qian YJ, Zhang HY: Survey of Toxoplasma gondii infection in pet dogs in Shanghai. Chin J Vet Parasitol 2006, 3:3-4, (in Chinese)

22. Lu J, Zhu DX, Hao FX, Liu J, He SZ: Survey of diseases in pet dogs in Taizhou. Ani Sci Vet Med 2009, 41:109-110, (in Chinese).

23. Huang SM, Zhou QP, Cui K, Huang ZS, Li QX: Survey and clinical treatment of toxoplasmosis canis in urban area of Haikou City. Chin Trop Med 2008, 8:1462-1392, (in Chinese).

24. Zhang DX, Zhang XP, Wen QP: Serological survey of Toxoplasma gondii infection in dogs and cats in Dongguan, Guangdong Province. Chin Ani Sci Vet Med 2007, 34:130-131, (in Chinese).

25. Yu YL, Fu L, Wang M: Serological survey of Toxoplasma gondii infection in dogs and cats in Beijing. Chin J Vet Med 2006, 42:7-9, (in Chinese).

26. Yuan WY, Ma K, Yang HL: Surveys of Toxoplasma infections in animals in Hebei Province. Chin J Schisto Cont 2004, 16:72-76, (in Chinese).

27. Dubey JP, Desmonts G: Serological responses of equids fed Toxoplasma gondii oocysts. Equine Vet J 1987, 19:337-339.

28. Dubey JP, Velmurugan GV, Alvarado-Esquivel C, Alvarado-Esquivel D, Rodriguez-Pena S, Martinez-Garcia S, Gonzalez-Herrera A, Ferreira LR, Kwok OC: Isolation of Toxoplasma gondii from animals in Durango, Mexico. J Parasitol 2009, 95:319-322.

29. Yan C, Yue CL, Yuan ZG, Lin RQ, He Y, Yin CC, Xu MJ, Song HQ, Zhu XQ: Molecular and serological diagnosis of Toxoplasma gondii infection in experimentally infected chickens. Vet Parasitol 2010, 173:179-83.

30. Bresciani KD, Costa AJ, Toniollo GH, Luvizzoto MC, Kanamura CT, Moraes FR, Peffi SH, Gennari SM: Transplacental transmission of Toxoplasma gondii in reinfected pregnant female canines. Parasitol Res 2009, 104:1213-1217.

31. Arantes TP, Lopes WD, Ferreira RM, Pieroni JS, Pinto VM, Sakamoto CA, Costa AJ: Toxoplasma gondii: Evidence for the transmission by semen in dogs. Exp Parasitol 2009, 123:190-194.

32. Zhang Y, Li H: Epidemiological investigation of toxoplasmiasis among high risk groups in Lanzhou District. Chin J Parasit Dis Cont 2005, 18:432-437, (in Chinese).

doi:10.1186/1756-3305-4-64

Cite this article as: Wu et al:: Seroprevalence of Toxoplasma gondii infection in pet dogs in Lanzhou, Northwest China. Parasites \& Vectors 2011 4:64.

\section{Submit your next manuscript to BioMed Central and take full advantage of:}

- Convenient online submission

- Thorough peer review

- No space constraints or color figure charges

- Immediate publication on acceptance

- Inclusion in PubMed, CAS, Scopus and Google Scholar

- Research which is freely available for redistribution

Submit your manuscript at www.biomedcentral.com/submit 